\title{
Analysis of Practical Teaching Methods for Logistics Management Major in Higher Vocational Colleges - Taking the Procurement Management Practice Course as an Example
}

\author{
Jing Yuan* \\ School of E-Commerce and Logistics, Jiangsu Vocational College of Business, Nantong 226000, Jiangsu Province, China \\ *Corresponding author: Jing Yuan, yuanjing20222022@163.com \\ Copyright: ( $) 2022$ Author(s). This is an open-access article distributed under the terms of the Creative Commons Attribution License (CC \\ BY 4.0), permitting distribution and reproduction in any medium, provided the original work is cited.

\begin{abstract}
As a teacher majoring in Logistics Management in higher vocational colleges with deep understanding of the course for many years and taking the Procurement Management Practice course as an example, this study selects the after-school cases in the "Purchase Price and Cost Control" chapter in the second edition textbook of Procurement Management Practice of Machinery Industry Press as the research subject of this case analysis. In addition, combined with the chapter content of this textbook, this paper expounds the teaching methods of practical training projects. In hope to provide some ideas for practical teaching, through research and analysis, there is a clearer understanding of the practical teaching of the core curriculum of Logistics Management major.
\end{abstract}

Keywords: Case analysis; Training projects; Procurement Management Practice

Online publication: January 20, 2022

\section{Introduction}

For practical courses, the best way is to integrate the practical part of the course into the work of the enterprise through school-enterprise cooperation, in which students will be involved in certain enterprises for a period of time. Some higher vocational colleges have enterprises in schools with mature production, learning, research, and innovation system, so students can naturally carry out practical exercises. However, the training situations of most higher vocational colleges are limited. At present, there is no way to completely break off from classroom teaching, and enterprises cannot include many students in the actual work at the same time.

To a certain extent, the practical teaching method can make up for the lack of practical operations. There are a large number of classic cases and training projects in the textbook of the procurement course, which allow the application of knowledge in each chapter and those before and after as well as give play to students' subjective initiative, active thinking, and problem-solving skills in situational projects. The practical teaching method is based on the Procurement Management Practice course, which will be described in detail by using case analysis and practical training projects. 


\section{Case analysis method}

\subsection{Case analysis}

Before any case analysis, students should be guided to understand the title and problems of the case, so that they can form a thinking direction in their minds. Then, according to the length and difficulty of the case content, students are given some time to read the case and think about the problems. Students then should link the knowledge learned in the chapter and their own cognition as the knowledge contents are not only limited to the procurement course. They should be analyzed according to the content of specific cases, using divergent thinking and combining with the knowledge of other courses in Logistics Management or Finance and Trade. There is no standard answer to the problems in case analysis. As long as the analysis is reasonable, it can be regarded as the answer to the problem.

\subsection{Specific examples}

Regarding the "Cost Analysis of Purchasing Guava Concentrated Juice by Acreage Foods," the source of this case and problems are discussed (the second edition textbook of Procurement Management Practice, edited by Chen Limin and published by Machinery Industry Press).

Acreage Foods is a multinational food processing enterprise in the United States. This company uses various concentrated fruit juices, soups, and condiments in its production. Betty is a veteran purchaser of the company responsible for purchasing fruit products required for production. One of her responsibilities is to negotiate the purchase contract of these ingredients with the supplier every year. Guava, one of the ingredients, grows and harvests seasonally in many countries around the world.

Upon checking an expense, it is found that the expenditure was paid to a guava grower and processor in the Philippines. Acreage Foods has worked with this high-quality supplier for many years. Guava is produced in a remote area of the Philippines. The fruit is usually transported to the processing plant for concentration and packaging, and then exported overseas. The series of products made from guava are famous for their delicacy, and the unique taste comes from the special processing method adopted by the supplier.

Guava concentrate is currently priced FOB (free on board) at $\$ 0.29 /$ pound. It is internally packed in silver foil, and each package weighs 50 pounds. It is packaged in cardboard boxes. These cartons are stacked on pallets, and each pallet is stacked with 40 cartons for loading into containers. Each container can hold 20 pallets, and they are shipped by sea. The shipping charge is $\$ 2,300$ per container. After arriving at a port, the containers are shipped to a local warehouse for storage at a cost of $\$ 250$ each. US Customs charges a tariff of $15 \%$ of the price of goods, excluding shipping. The company needs a container of guava concentrate every month.

Containers are stored locally until they are picked up for processing at a monthly inventory cost of $\$ 5.50$ per pallet.

In addition, the warehouse charges an entry and exit fee of $\$ 6$ per pallet as administrative costs. The cost of capital of Acreage Foods is $18 \%$, assuming that the demand for guava concentrate remains unchanged throughout the year.

When the manufacturer needs guava juice concentrate, the container is transported from the warehouse by a local transportation company, with a freight rate of $\$ 150$ per container and a quality control cost of about $\$ 2$ per pallet. The company estimates that due to the characteristics of the product, there will be certain losses in the purchase and storage of guava concentrated juice. When incorporated into the company's product budget, $97 \%$ of guava concentrated juice is calculated, while the other $3 \%$ is the product loss. These losses cannot be exchanged with the manufacturer. 
Those spoiled guava concentrated juice not found in advance shall be removed from the store shelves and recycled. The out-of-pocket cost for each product recycling is $\$ 20,000$, and the supplier shall not be liable for making up for these losses. Company records show that such incidents occur on average once every eight months. In addition, the company's accounting policy requires that $15 \%$ of the total purchase amount should be set aside as management cost.

Question 1: Analyze the procurement cost structure and its influencing factors.

Question 2: Discuss the effective ways to control and reduce the total procurement cost.

\subsubsection{Analyzing Question 1}

The purchase cost components (in USD).

(1) The price of goods is the cost of purchasing the goods: $0.29 * 50 * 40 * 20=11,600$

(2) Tariff: $11,600 * 15 \%=1,740$

(3) Freight: 2,740

Sea freight: $2,300 * 1=2,300$

Road freight (port to warehouse): $250 * 1=250$

Transportation from warehouse to factory: $150 * 1+2 * 20=190$

(4) Storage fee: $(5.5+6) * 20=230$

(5) Management cost: $[(1)+(2)+(3)+(4)] * 15 \%=(11,600+1,740+2,740+230) * 15 \%=2,446.5$

(6) Loss cost: $(1) * 3 \%+20,000 / 8=2,848$

The above shows six cost components. Through calculation and analysis, it can be concluded that some costs are inevitable, such as the purchase cost of goods, tariff (the cost ratio determined by the customs), sea freight, part of storage cost, part of management cost, and part of loss cost. There are some costs that do not occur or occur less frequently. The factors affecting the occurrence of costs are complex. Question 2 will be on how to avoid or control them.

\subsubsection{Analyzing Question 2}

In order to control and reduce the cost, it is necessary to study the above six aspects, and then carefully ruminate in consideration of the statement of the case content.

(1) The price of goods is fixed in the form of FOB, and the FOB value needs to be considered.

It is more cost-effective for the seller to use FOB. All sea freight and marine risks are borne by the buyer. For Acreage Foods, the costs and risks are greater. If possible, it should be changed to CIF (cost, insurance, and freight), so that the price of goods and the procurement cost can be reduced. However, based on the background of this case, Acreage Foods has chosen this remote guava processor in the Philippines because it is able to grow and process high-quality guava concentrates and the company has worked with this processor for many years. It can be appreciated that the company in Philippines is monopolizing the industry with good quality products. It is difficult to estimate whether Acreage Foods wants to reduce the procurement cost at CIF price. In order to reduce the cost of purchasing guava concentrated juice, one can change the supplier. As stated above, it can be seen that guava concentrated juice is not only grown and processed in Philippines, but also in many other countries in the world. Acreage Foods can consider looking for a more suitable supplier and can reach a CIF transaction. Needless to say, Acreage Foods can use the idea of 
changing suppliers as a bargaining chip to negotiate with their cooperating suppliers in Philippines, so as to convert the FOB price into CIF price, thus reducing the cost of purchasing guava concentrated juice.

(2) Consider the material cost of the packaging

The inner packaging material of guava concentrated juice is silver foil. The cost of silver foil is relatively high. Other materials with the same packaging effect with lower cost and has the feature of environmental protection can be considered, so as to control the cost to a certain extent.

(3) Reduction of road freight

There are two types of road freight: the cost from port to warehouse and from warehouse to factory. In order to reduce the road freight, the warehouse can be relocated to adjacent areas around the factory. When the factory needs to produce guava concentrated juice, it can use light trucks or forklifts inside the factory, so that the factory can also use the required raw materials at any time, thus improving the logistics and production efficiency.

(4) Reduction of storage expenses and management costs

Intelligent equipment, unmanned warehouse, warehouse management system (WMS), and warehouse control system (WCS) can be used to reduce labor costs and improve warehouse material turnover as well as space efficiency. Advanced warehouse management systems and equipment require enterprises to have financial strength to invest in construction, but if it involves warehouse management under supply chain integration, the production factory can outsource the warehouse and control the storage fee and management cost of the enterprise to a certain extent.

(5) Reduction of loss cost

The loss cost comes from two aspects: inevitable natural loss and loss caused by corruption and deterioration which can be avoided through real-time monitoring. The former meets the loss standard and can hardly be reduced, but the latter is caused by the negligence of management and can be avoided. If the enterprise monitors in real time, it is possible to determine those products that are approaching the shelf life. Then, it is necessary to find ways to deal with it. It can be dealt with in time through marketing means, discounts, and bundle sales, so as to minimize the loss, and eventually have a certain control over the loss cost.

This question is the continuation and expansion of the content based on the answer to the first question. It involves the practical application of the theoretical knowledge of the chapter and even the integrated application of other courses in Logistics Management.

\section{Practical training project method}

\subsection{Training projects}

During the teaching and training week, the training simulation project of the procurement course can be arranged in such a way to carry out teaching, and the theme can be set. If there is procurement training software or supply chain teaching software, it can be used to assist the training.

The class can be divided into groups of three to five students, with each group representing an enterprise. The students should then name their own enterprise and select a student to be the group leader, who would be the general manager of the enterprise. Then, the group members should be assigned positions, roles, rights, and responsibilities.

After the grouping, teachers should explain the tasks and requirements of the training project, and each task should be scored. Finally, the total score can be obtained from self-evaluation within the group, mutual evaluation between groups, and the teacher's evaluation. The first, second, and third prizes should be 
rewarded according to the score, so as to encourage students' participation and motivation.

Through practical training, students can give full play to their learning initiative and actively participate in the completion of the project. At the same time, it can also cultivate students' awareness of teamwork, improve their comprehensive quality, and train them to become professional procurement talents.

\subsection{Specific examples}

\subsubsection{Theme}

Enterprises need to purchase various materials to produce a certain product. How then to select appropriate suppliers and acquire the required materials?

\subsubsection{Requirements}

(1) According to the theme, three to five students would form a group, establish an enterprise, and name the enterprise. The positions and roles of the group members are determined, and their rights and responsibilities are clarified.

(2) Enterprises are required to make purchase plans and budgets.

(3) Appropriate cooperative suppliers are selected through bidding procurement.

(4) Procurement negotiation and contract signing.

(5) Contract tracking, procurement process control, and supplier relationship maintenance.

(6) Procurement performance evaluation.

\subsubsection{Time}

For a period of one week, the specific schedule is as follows:

(1) Stage I: Issue the procurement plan, procurement budget table, bidding document, tender document, and supplier database, as well as make corresponding speeches and explanations on day 1 and 2.

(2) Stage II: Issue the procurement negotiation records, procurement contracts, supplier evaluation reports, simulation scenarios, and speech explanations on day 3 and 4.

(3) Stage III: Issue the contract tracking record form, procurement process control and early warning scheme, as well as other materials provided, and make corresponding speeches and explanations on day 5 and 6.

(4) Stage IV: Final group presentation and compete for the best group on day 7.

Teachers would provide corresponding guidance in each stage.

\subsubsection{Report}

(1) The corresponding report should be completed in each stage, and the materials issued in each stage should be attached in the report.

(2) Analyze, study, and deal with the actual situation encountered in the training.

(3) The authenticity and feasibility of various schemes, statements, and data should be demonstrated to reflect rationality. 


\subsubsection{Assessment}

(1) Whether the division of labor of the group is clear, whether the responsibilities are clear, whether there is teamwork spirit among the group members, and the team leader evaluates and scores each member of the group.

(2) Whether the relevant information and data are detailed, accurate, specific, and reasonable.

(3) Whether the training report format of each student is standardized.

(4) Whether the team's report and explanation of each stage are detailed, comprehensive, and clear.

(5) Whether the questions raised by teachers and other students can be answered quickly and accurately.

(6) Teachers should conduct stage assessment for each group and share the assessment scores in each stage.

(7) Comprehensive evaluation should be according to individual and team performance, self-evaluation, mutual evaluation, and teacher's evaluation; upon obtaining the final score, reward the best group and individuals who performed well for encouragement.

\section{Conclusion}

Case analysis and training projects are two key and important means in teaching. When using the two methods, it is important to arrange more time for teaching, focus on the use of the two teaching methods, and integrate the current hot spots in the industry to stimulate students' learning enthusiasm and interest in participating. At the same time, the ideological and political content of the course is interspersed, with emphasis on the spirit of national unity. The country should become a logistics power and enhance students' sense of patriotism through teaching and fun as well as train students to become real talents with feelings, skills, and responsibility.

\section{Disclosure statement}

The author declares that there is no conflict of interest.

\section{References}

[1] Chen L, 2020, Procurement management practices (2nd Edition), Machinery Industry Press, Beijing. 